\title{
Fault Ride Through Technique for DFIG-based Wind Turbines Under Grid Three-phase Faults
}

\author{
Peter Makolo ${ }^{1,2}$, Jackson J. Justo ${ }^{1}$, Francis Mwasilu ${ }^{1}$ and Ramon Zamora ${ }^{2}$ \\ ${ }^{1}$ Department of Electrical Engineering, University of Dar es Salaam - Dar es Salaam, Tanzania \\ ${ }^{2}$ Department of Electrical and Electronic Engineering, Auckland University of Technology - Auckland, New Zealand
}

\begin{abstract}
In modern power systems with increasing penetration of wind turbines (WTs), improvement of low voltage ride through (LVRT) capability of WTs equipped with doubly-fed induction generators (DFIGs) is an important topic. Thus, this paper proposes an LVRT strategy and compares its performance with a widely used conventional LVRT strategy. The proposed strategy is designed with a capacitor connected in series with an inductor and both are connected in parallel to a resistor. This configuration is then connected to the ac side of the rotor side converter (RSC) via an R-L circuit. To validate the performance of the proposed scheme, three phase fault condition is simulated and analysed. Based on simulation results obtained in MATLAB/Simulink, there is significant improvement achieved in the stated objectives compared to the conventional LVRT scheme.
\end{abstract}

Index Terms--Conventional crowbar scheme, doubly-fed induction generator (DFIG), fault ride through (FRT), low voltage ride through (LVRT), and wind turbines (WTs).

\section{INTRODUCTION}

Currently the world is developing towards cleaner and greener environment, leading to the concept of increasing penetration of distributed generation from renewable energy sources (RES). However, integrating them in the main grid is a challenging subject as they may decrease the quality and reliability of the grid. The main reasons to these setbacks are their stochastic nature of power generation and their low or no inertial response capability to dynamics $[1,2]$.

As one of the most promising RES, wind energy has attracted much attention [3-7]. Compared with other kinds of wind driven generators, doubly-fed induction generator (DFIG) has a lower cost and a smaller size due to its lowcapacity back-to-back power converters. Therefore, DFIG has become popular and is widely used [6]. However, during grid fault the voltage dip at the point of common coupling (PCC) may seriously affect the stator of the DFIG which is directly connected to the grid, resulting in a transient stator current [3]. Due to magnetic coupling between the stator and rotor windings, high voltage and a large current in the rotor windings are induced. As a result, the protection system may disconnect the DFIG from the grid, leading to cascaded system failures [8]. At the same time, the power converter switching devices may be damaged due to their low power ratings.

Furthermore, when the voltage at the PCC drops suddenly due to grid fault, there is a sudden change in the stator flux of the generator. In that case, demagnetization occurs, and hence electromagnetic torque decreases as compared to mechanical torque from WT. Acceleration of the rotor then occurs which can cause over-current across the stator and rotor circuits. This leads to increase in reactive power demand of induction generator drawn from the grid [9]. The generated over-current may cause severe damage to the semiconductor devices in the rotor side converter (RSC) and large fluctuations of the dc-link voltage. Due to these concerns, necessary measures have been taken in the field of wind energy to control DFIG. However, specific strategy to protect DFIG during faults or fault ride through (FRT) is still an open research area to work on.

To address these concerns, grid codes must be fulfilled by any distributed generation systems such as WTs connected to the grid. The connection agreement sets out specific technical requirements to be fulfilled by the wind farm as in $[8,10,11]$ which include:

- Outlining fault duration, fault types, permissible changes to post fault power.

- Frequency range, with time durations for extreme conditions, permissible power reduction at frequency extremes, if any.

- Controllability of the output power, e.g., automatic frequency control, including speed of response.

- Reactive power operating range, e.g., the wind farm to be able to operate with a specified power factor.

- Voltage control capability, etc.

Some researchers have presented various protection strategies of DFIG to protect the rotor from over current and over voltage, as well as to achieve the low voltage ride through (LVRT) capability during grid faults. These protection strategies include: i) installation of extra protection circuits, ii) modification of the control strategies or using advanced control strategies, and iii) installation of FACTS devices like SVC and STATCOMs [12]. As for the installation of protection circuits, a rotor-side crowbar circuit has been 
reported as the most widely used LVRT strategy for DFIG wind turbines. In this case, the analysis of transient response of DFIG during fault and the calculation of transient current considering rotor-side crowbar circuit is described in [13, 14]. Moreover, the crowbar circuit and the DC chopper circuit are both used to limit the rotor current and DC bus voltage in [13]. Also, a series dynamic resistor integrated with the conventional crowbar is presented in [15]. Furthermore, a direct control of the negative sequence components of rotor current by using multiple proportional resonant controller avoiding the need of notch filters is discussed in [16]. However, this paper proposes a new LVRT configuration and presents a detailed analysis entitled to enhance the fault-ride through (FRT) capability of DFIG to improve the power quality of the system as will be explained in detail in section III.

The rest of the paper is organized as follows: after the general introduction which is presented in Section I, Section II briefly highlights about the basic modelling of the DFIG based WT. Next, the state-of-art of conventional LVRT strategy and the proposed design are detailed presented in section III. Section IV presents the simulation results, analysis and discussion on various case studies while the conclusion is presented in Section V.

\section{MATHEMATICAL MODEL OF WIND TURBINE EQUIPPED WITH DFIG}

\section{A. Wind speed resources and aerodynamic equations}

As wind speed $\left(V_{w}\right)$ increases with height above the ground, the calculation of wind speed at a given height is carried out by applying the power law expressed by (1) as in [17].

$$
\frac{V_{w-h}}{V_{w-r e f}}=\left(\frac{H}{H_{r e f}}\right)^{\gamma},
$$

where, $\gamma$ is the power law exponent, $V_{w-r e f}$ is the reference wind speed in $(\mathrm{m} / \mathrm{s})$ at the reference height $H_{\text {ref }}(\mathrm{m})$ and $V_{w-h}$ is the wind speed in $(\mathrm{m} / \mathrm{s})$ at the height $H(\mathrm{~m})$.

In wind studies, wind speed distribution is a key factor in wind resource assessment of a given site. Various models, such as Weibull, Rayleigh, Lognormal, and Gamma are theoretically applied to fit the distribution of wind speed data. Several studies showed that the Weibull distribution model proved to be the best one due to its great flexibility and simplicity [8]. The general form of Weibull distribution function for wind speed data is expressed by (2) as in [10].

$$
f\left(V_{w}\right)=\left(\frac{k}{c}\right) \times\left(\frac{V_{w}}{c}\right)^{k-1} \exp \left[-\left(\frac{V_{w}}{c}\right)^{k}\right],
$$

where, $f\left(V_{w}\right)$ is the probability density function of observed wind speed data, and $k$ (which is dimensionless) and $c(\mathrm{~m} / \mathrm{s}$ ) are the shape and scale parameters, respectively.

The modelled wind speed in (1) and (2) is passed through the wind turbine blades which are represented by their efficiency of extracting power from the moving air. This efficiency is called the coefficient of aerodynamics (i.e., $C_{p}$ ) which is a function of tip-speed ratio $(\lambda)$ and pitch angle $(\beta)$ of the blades, i.e., $C_{p}(\lambda, \beta)$ [17]. The power extracted by the WT blades is given by (3).

$$
P_{m}=\frac{1}{2} \rho A V_{w}^{3} C_{p}(\beta, \lambda),
$$

where, $\rho$ is the air density, $A$ is the area swept by WT blades, $V_{w}$ is the wind speed, $C_{p}(\lambda, \beta)$ is given by (4) and the tip-speed ratio $(\lambda)$ is given by $(5)$.

$$
\begin{gathered}
\mathrm{C}_{\mathrm{P}}(\lambda, \beta)=0.22\left(\frac{116}{\lambda_{\mathrm{i}}}-0.4 \beta-5\right) \mathrm{e}^{\left(-12.5 / \lambda_{\mathrm{i}}\right)}, \\
\lambda=\frac{\omega_{\mathrm{T}} \times \mathrm{R}_{\mathrm{T}}}{\mathrm{V}_{\mathrm{w}}},
\end{gathered}
$$

where, $w_{T}$ is the turbine's rotor rotational speed in $(\mathrm{rad} / \mathrm{s})$ and $\mathrm{R}_{\mathrm{T}}$ is the turbine's rotor radius in $(\mathrm{m})$.

\section{B. DFIG Control strategy}

To achieve a steady-state operation of the wind turbine equipped with DFIG, the RSC control adjusts the stator active power $\left(P_{s}\right)$ and reactive power $\left(Q_{s}\right)$ supplied by DFIG by regulating the q- and d-axis rotor currents $\left(i_{q r}\right.$ and $\left.i_{d r}\right)$, respectively. The $P_{s}$ reference is obtained from a look-up table (provided by the wind plant operator) representing the maximum power point tracking (MPPT) algorithm [8]. Meanwhile, grid-side converter (GSC) controller operates in grid AC voltage reference frame (GCVRF) and regulates the dc-link voltage $\left(V_{D C}\right)$ and the reactive power $\left(Q_{g}\right)$ exchange with the PCC regardless of the direction of the rotor power flow. It operates in synchronism with the AC voltage whereby a built-in model of a phased-locked loop (PLL) is used to determine the voltage angle [9]. In this study, non-windup proportional integral (PI) controllers are used to define the rotor current and voltage set-points while rotor voltage, $V_{r}$, is obtained by defining the modulation index as in (6) [17].

Modulation Index $=2 \sqrt{2} V_{r} / \sqrt{3} V_{D C}$,

where, $V_{D C}$ is the dc link voltage.

Following the increase in penetration of wind turbines in electric power systems over the last decade, the grid codes require these generators to contribute to the power system stability. Therefore, it is important to consider the facts that, during grid faults these WTs are more vulnerable to disturbances when one or more voltages at the PCC suddenly drop close to zero. This will result in a large transient current at the stator terminals [12]. A relevant topic, the mechanisms applied to enhance the operating capability of the DFIG when grid faults occur in the interconnected network are discussed in the next section.

\section{LOW VOLTAGE RIDE THROUGH STRATEGIES AND PROPOSED DESIGN}

\section{A. Conventional protection circuit}

A conventional crowbar is a protection circuit which is incorporated with only resistors. It is installed at the slip-rings of the DFIG, i.e., between rotor windings terminals and acside of the RSC. When a fault is detected, the switching 
control engages the crowbar by short circuiting the generator rotor through its resistor $\left(R_{c r w}\right)$. With the crowbar protection circuit, the power converter (RSC) is temporarily blocked, and the generator excitation control is usually lost $[9,18,19]$. In this mode of operation, the DFIG is transformed into the conventional induction machine, i.e., squirrel-cage induction generator (SCIG) with very high slip value (s).

The SCIG temporary operating characteristics are noticed by its behavior of drawing reactive currents from the grid via the generator stator to support generator magnetization process. The result of such scenario is a further decrease of network voltage at the PCC which in turn may lead to a failure complying with the grid-code requirements $[9,19]$.

\section{B. Proposed protection circuit}

Fig. 1 presents the proposed crowbar protection circuit. The proposed strategy is designed with a capacitor connected in series with an inductor and both are connected in parallel to a resistor. This configuration is then connected to the ac side of the rotor side converter (RSC) through an R-L circuit making up $Z^{\prime \prime}{ }_{c r}$. The major functions of the capacitor, $X_{C \text {-crw }}$, in the proposed crowbar protection circuit are to eliminate the ripples generated in the rotor voltage while the inductor, $X_{L-c r w}$, reduces the ripple in rotor current to protect the converters as well as the dc-link capacitor. Unlike the conventional crowbar circuit which has only resistors and which blocks the RSC operation when activated, the proposed scheme is entitled to maintain the RSC connection to the rotor windings of the DFIG during fault conditions to provide un-interruptible power supply with improved performance to the grid.

During grid three phase fault, the inrush rotor current normally increases to more than its threshold value (i.e., $I_{r}>$ $I_{r t h}$ ). In this case, the high inrush rotor current must be channeled through the circuit connected to the rotor winding terminals and ac-side terminals of the RSC to avoid damage of the converter.

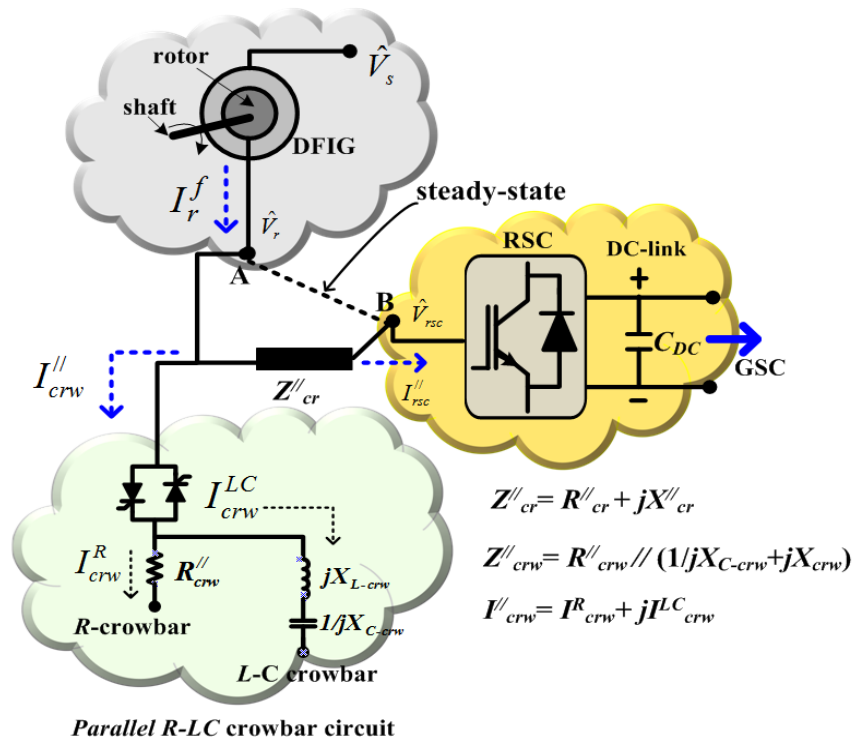

Figure 1. Proposed protection circuit configuration for DFIG wind turbine.
Neglecting the switching transients of the circuit, it can be said that when the proposed crowbar protection is integrated with series R-L circuit, the RSC connection to the rotor winding terminals is partially maintained compared to when only crowbar circuit is applied. In that case, its excitation control is also partially maintained since the generator is partly grounded via the crowbar and partly connected to the RSC through the series R-L branch. In other words, this operating phenomenon transforms the DFIG characteristics into a temporary state in which the induction machine behaves partially as the wound rotor induction generator because of being partly connected to the RSC via the R-L series branch and partially operates as SCIG following its partly shortcircuiting of the rotor windings through the crowbar circuit.

The main objectives of the proposed LVRT topology are: minimizing the magnitude of rotor fault currents, maintaining a constant dc-link voltage and overall improved dynamic responses of the DFIG wind farm. Based on simulation results obtained in MATLAB/Simulink package in the next section, it is observed that there is significant improvement in the transient response of the DFIG WT during fault.

\section{PERFORMANCE VALIDATION}

To verify the performance of the proposed protection circuit, simulation studies are conducted using MATLAB/Simulink for a 1.5 MW DFIG based WT with and without the protection circuits. In this study, conventional crowbar protection circuit and proposed crowbar protection integrated with series R-L circuit are considered for simulation and comparative study analysis. For simplicity purposes and considering the facts that grid faults are of short duration, the following assumptions are taken into consideration during modelling process and simulation studies: mechanical time constant $\left(T_{m}\right)$ of the wind turbine blades is assumed to be larger than that of the generator $\left(T_{g}\right)$, wind speed variations between fault occurrence and fault clearance are neglected, to ensure the continuous safe operation of the power converters and dc-link capacitor. Then, the converter current $\left(I_{r s c}\right)$, dcvoltage $\left(V_{d c}\right)$ and modulation index are investigated. Lastly, parameters' values of the protection circuit are selected through extensive simulation studies while considering the limitations of both RSC switching devices and dc-link capacitor. The ON/OFF periods of the power electronic switching devices used for the protection circuits are assumed to be negligible.

\section{A. Steady-state responses}

During steady-state performance with the rated wind speed $V_{w}=12 \mathrm{~m} / \mathrm{s}$, the response of the current into the RSC, $I_{r s c}=I_{r}$, rotor voltage, dc link voltage, $V_{d c}$ and PWM index are presented for simulation time of $12 \mathrm{~s}$. In this case, the rated (nominal) values of $I_{r s c-N o m}=I_{r}=1.77 \mathrm{kA}, V_{d c-N o m}=1.2 \mathrm{kV}$, rms values of $V_{r}=0.8 \mathrm{kV}$, and modulation index, $M=0.67$ are used. Fig. 2 shows the steady-state performance of a single wind turbine equipped with DFIG configuration. This shows that the selected parameters are maintained at their desired values. 

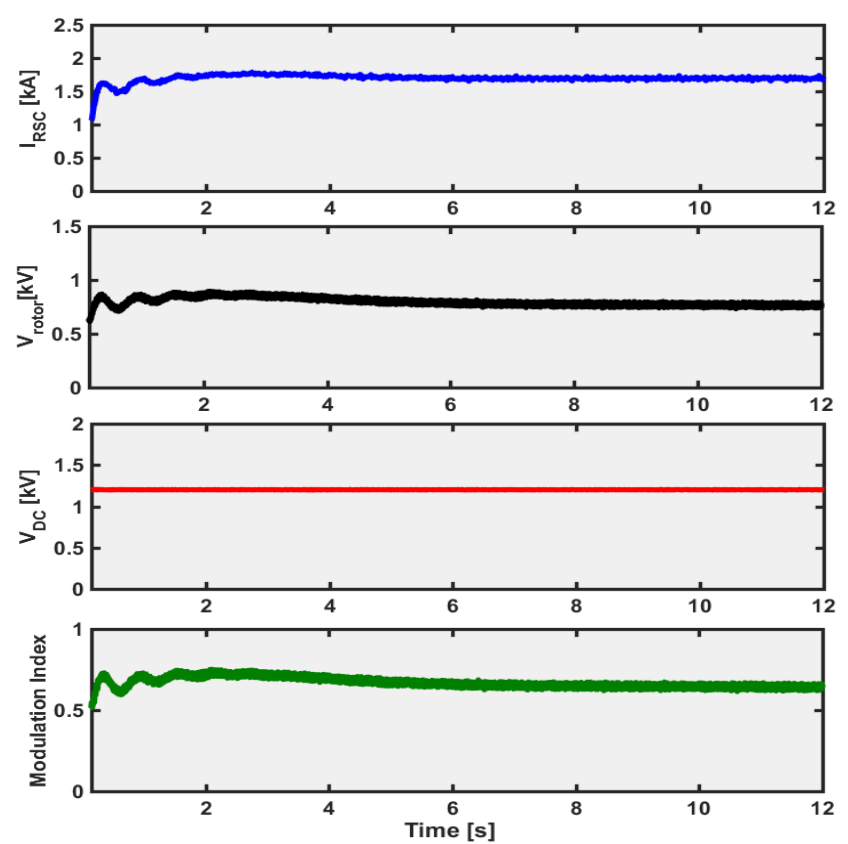

Figure 2. Steady-state performance of the DFIG wind turbine under normal operating condition: converter currents $\left(I_{r s c}\right)$, rotor voltage, dc-link voltage $\left(V_{d c}\right)$, and modulation index.

\section{B. Transient-state responses: balanced 3-phase fault}

To validate the performances of the protection circuits, a severe 3-phase balanced grid-fault condition is initiated at $t=$ $7.5 \mathrm{~s}$ and cleared at $t=7.65 \mathrm{~s}$. The fault is initiated at $3 \mathrm{~km}$ from the PCC leading to a voltage dip with magnitude of the more than $85 \%$ at the PCC. Results obtained without any protection are presented in Fig. 3.
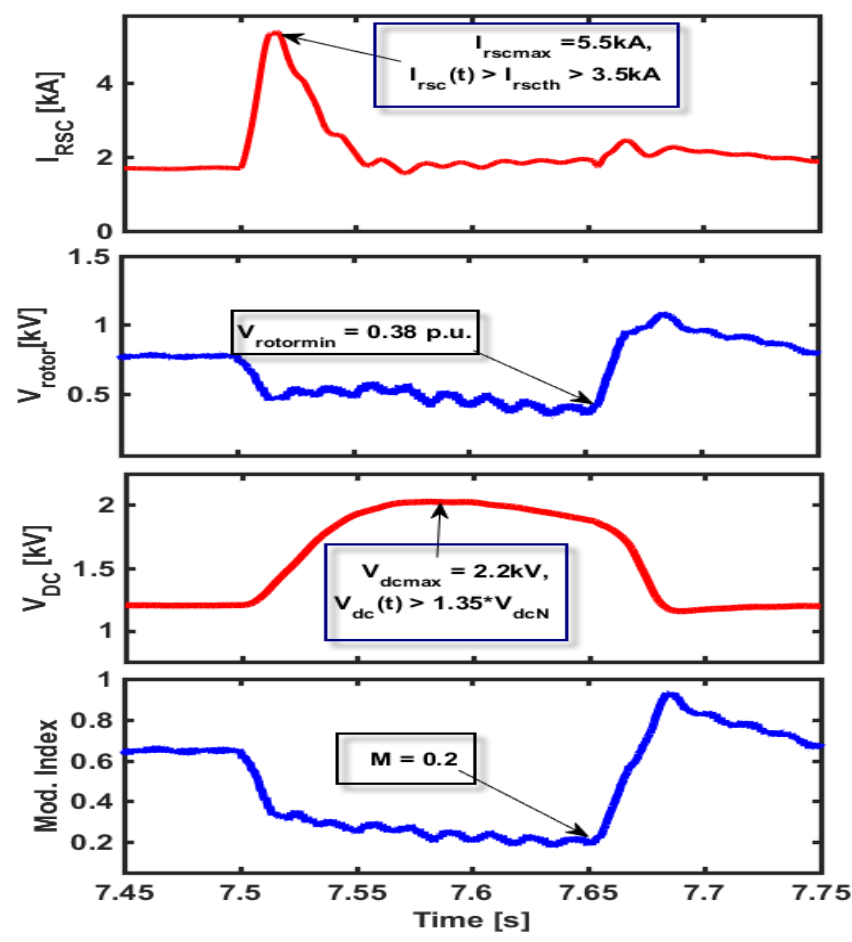

Figure 3. Transient response of the DFIG wind turbine under 3-phase short circuit condition: converter currents $\left(I_{r s c}\right)$, rotor voltage, dc-link voltage $\left(V_{d c}\right)$, and modulation index.
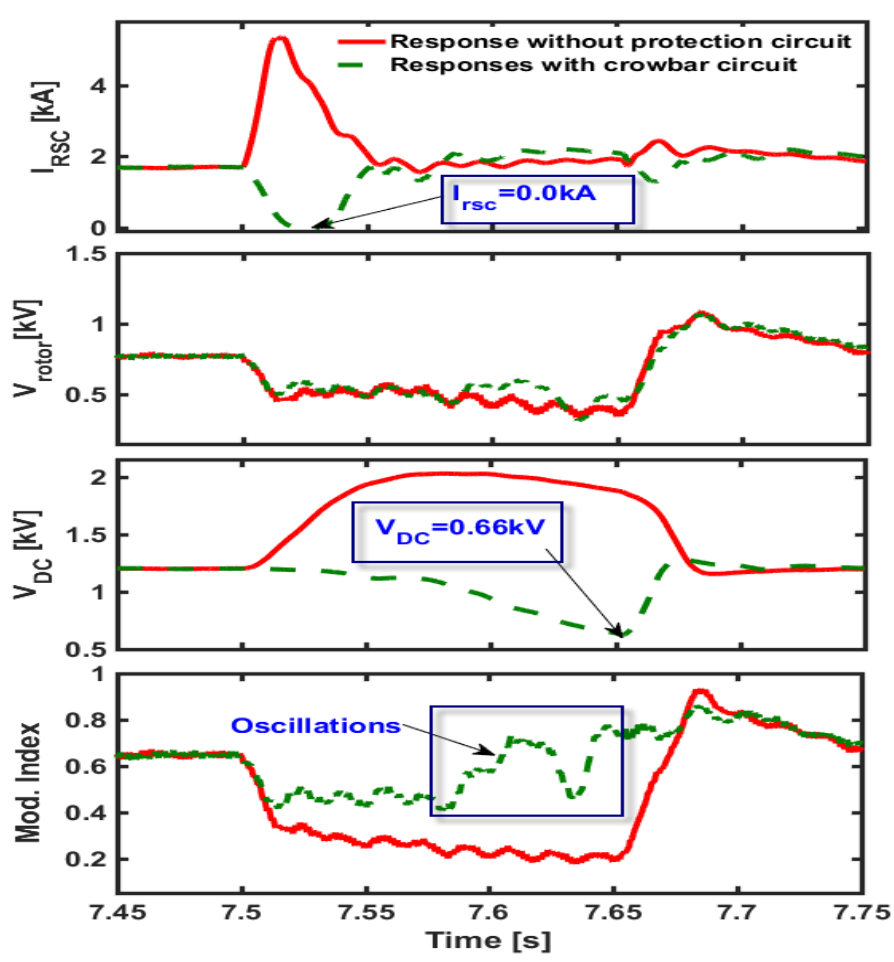

Fig. 4. Transient response of the DFIG wind turbine under 3-phase short circuit condition with and without crowbar circuit: converter currents $\left(I_{r s c}\right)$, rotor voltage, dc-link voltage $\left(V_{d c}\right)$, and modulation index.

Examining the waveforms shown by the red solid-lines on Fig. 3, the peak value of inrush current rises to above $5.5 \mathrm{kA}$ (more than 200\% increase). This is higher than its threshold value which in this case $I_{r s c-t h}=3.54 \mathrm{kA}$ (i.e., $I_{r s c-t h}=2 I_{r s c-N o m}$ ) immediately after the fault initiation. This indicates a serious risk to the power electronics devices which have low rating for DFIG configuration. Moreover, $V_{d c}$ response shoots to above $1.95 \mathrm{kV}$ which is unsafe to the dc-link capacitor while the rotor voltage oscillates and immediately stabilizes after fault clearance. Dip in PCC voltage leads to a dip in rotor voltage, $V_{r}$, increase in $V_{d c}$, and the modulation index decreases to a minimum value of 0.2 at $t=7.65 \mathrm{~s}$.

Fig. 4 shows the comparative results when the conventional crowbar protection circuit is engaged (green dotted line) and when not engaged (red solid line). In this case, inrush current is reduced to zero, i.e., $I_{r s c} \approx 0 \mathrm{kA}$, at time 7.53 $\mathrm{s}$, which indicates that the RSC operation is temporarily disabled regardless of the continuous operation of the generator. The dc link voltage is also reduced from $1.9 \mathrm{kV}$ to $1.19 \mathrm{kA}$ as its maximum value. Although these oscillations are within the safe operating area (SOA) as the maximum value is less than 1.35 p.u., they indicate that the transfer of power between the dc link and the PCC is seriously affected due to deactivation of the RSC. Also, the modulation index is maintained within its pre-fault value although it significantly oscillates with its minimum value of 0.44 occurring $14 \mathrm{~ms}$ after the fault initiation.

Fig. 5 with the proposed protection circuit simulation result (black dotted line) depicts the improved performance. It is noted that the improved minimum value of modulation index to 0.41 occurs at $7.64 \mathrm{~s}$ with less oscillations. Inrush 
rotor current is below 2p.u. These responses under the proposed protection circuit indicate that the DFIG excitation control is well maintained and hence improved responses during transient state are achieved. The results reveal the advantage of introducing series L-C elements in the crowbar branch which helps to improve the current response which could not be the case for conventional crowbar protection circuit. This means that, the $\mathrm{R} / / \mathrm{L}-\mathrm{C}$ crowbar branch with the new introduced capacitance parameter effectively compensates the fluctuation of the current to the ac-side of RSC.
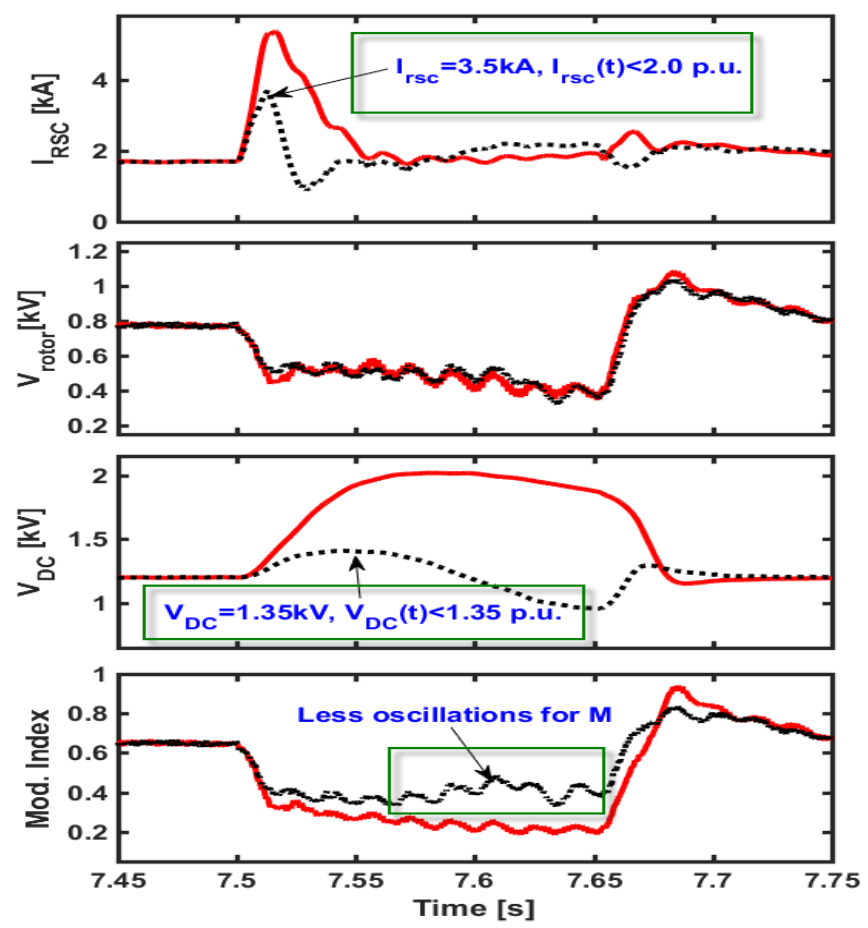

Figure 5. Transient response of the DFIG wind turbine under 3-phase short circuit condition with and without proposed protection circuit: converter currents $\left(I_{r s c}\right)$, rotor voltage, dc-link voltage $\left(V_{d c}\right)$, and modulation index.

\section{CONCLUSION}

This paper proposed a low voltage ride through (LVRT) scheme to enhance the fault ride-through capability of the DFIG based WTs under grid three-phase faults. The performance comparison between the proposed and conventional LVRT schemes was carried out through simulation results and analysis. The effectiveness of the proposed scheme was verified via MATLAB/Simulink software and the results were compared with those of the conventional schemes for the rotor overcurrent and dc-link overvoltage responses. From the comparative results analysis, it was found out that the proposed LVRT scheme could provide good transient responses by avoiding the loss of power control unlike the conventional LVRT schemes. In fact, with the proposed LVRT scheme the reactive power support can easily be enhanced to support the terminal voltage as per most grid-code requirements. This further shows that, by employing the proposed LVRT scheme, additional hardware to protect the DFIG based WTs may be avoided. As the result, the system overall cost can be minimized while system reliability as well as the efficiency can be highly improved.

\section{REFERENCES}

[1] M. H. Bollen and F. Hassan, Integration of distributed generation in the power system. John wiley \& sons, 2011.

[2] Q.-C. Zhong and G. Weiss, "Synchronverters: Inverters that mimic synchronous generators," IEEE Transactions on Industrial Electronics, vol. 58, no. 4, pp. 1259-1267, 2011.

[3] G. Pannell, D. J. Atkinson, and B. Zahawi, "Minimum-threshold crowbar for a fault-ride-through grid-code-compliant DFIG wind turbine," IEEE Transactions on Energy Conversion, vol. 25, no. 3, pp. 750-759, 2010.

[4] R. Zamora and A. K. Srivastava, "Controls for microgrids with storage: Review, challenges, and research needs," Renewable and Sustainable Energy Reviews, vol. 14, no. 7, pp. 2009-2018, 2010. P. Makolo, "Wind Generator Co-Simulation with Fault Case Analysis," Master of Science Thesis), Chalmers University of Technology, Department of Energy and Environment, 2013.

[6] G. Rashid and M. H. Ali, "Fault ride through capability improvement of DFIG based wind farm by fuzzy logic controlled parallel resonance fault current limiter," Electric Power Systems Research, vol. 146, pp. 1-8, 2017.

[7] M. S. El Moursi and H. Zeineldin, "A parallel capacitor control strategy for enhanced FRT capability of DFIG," IEEE Transactions on Sustainable Energy, vol. 6, no. 2, pp. 303-312, 2015.

[8] J. John Justo and K.-S. Ro, "Control strategies of doubly fed induction generator-based wind turbine system with new rotor current protection topology," Journal of Renewable and Sustainable Energy, vol. 4, no. 4, p. 043123, 2012.

[9] S. Swain and P. K. Ray, "Short circuit fault analysis in a grid connected DFIG based wind energy system with active crowbar protection circuit for ridethrough capability and power quality improvement," International Journal of Electrical Power \& Energy Systems, vol. 84, pp. 64-75, 2017.

[10] J. J. Justo, F. Mwasilu, and J.-W. Jung, "Doubly-fed induction generator based wind turbines: A comprehensive review of fault ride-through strategies," Renewable and sustainable energy reviews, vol. 45, pp. 447-467, 2015.

[11] J. J. Justo, F. Mwasilu, and J.-W. Jung, "Enhanced crowbarless FRT strategy for DFIG based wind turbines under three-phase voltage dip," Electric Power Systems Research, vol. 142, pp. 215226, 2017.

[12] J. Ouyang and X. Xiong, "Dynamic behavior of the excitation circuit of a doubly-fed induction generator under a symmetrical voltage drop," Renewable Energy, vol. 71, pp. 629-638, 2014.

[13] M. Dicorato, G. Forte, and M. Trovato, "Wind farm stability analysis in the presence of variable-speed generators," Energy, vol. 39, no. 1, pp. 40-47, 2012.

[14] L. Xu, L. Yao, and C. Sasse, "Comparison of using SVC and STATCOM for wind farm integration," in Power System Technology, 2006. PowerCon 2006. International Conference on, 2006, pp. 1-7: IEEE.

[15] P. Sun, J. Li, C. Wang, and X. Lei, "A generalized model for wind turbine anomaly identification based on SCADA data," Applied Energy, vol. 168, pp. 550-567, 2016.

[16] S. Tohidi and M.-i. Behnam, "A comprehensive review of low voltage ride through of doubly fed induction wind generators," Renewable and Sustainable Energy Reviews, vol. 57, pp. 412-419, 2016.

[17] G. Abad, J. Lopez, M. Rodriguez, L. Marroyo, and G. Iwanski, Doubly fed induction machine: modeling and control for wind energy generation. John Wiley \& Sons, 2011.

[18] K. E. Okedu, S. Muyeen, R. Takahashi, and J. Tamura, "Wind farms fault ride through using DFIG with new protection scheme," IEEE Transactions on Sustainable Energy, vol. 3, no. 2, pp. 242-254, 2012.

[19] S. Liu, T. Bi, K. Jia, and Q. Yang, "Coordinated fault-ridethrough strategy for doubly-fed induction generators with enhanced reactive and active power support," IET Renewable Power Generation, vol. 10, no. 2, pp. 203-211, 2016. 